\title{
EDITORIAL
}

Editor-in-Chief

\section{We need to value research quality more than quantity}

\author{
Lisa A. Harvey ${ }^{1}{ }^{1}$
}

Received: 27 August 2020 / Accepted: 27 August 2020

(c) International Spinal Cord Society 2020

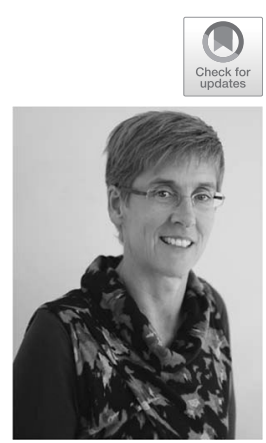

It is the quality, not the quantity, of research that make the biggest difference to the lives of people with spinal cord injuries (SCI). That is not to suggest that more investment in research is not welcome, but there is little value in producing more research if that research does not answer important questions. Unfortunately, there are many pressures that cause researchers to focus on producing a large quantity of research rather than high quality research. For example, researchers' publication rates inform decisions about grants, promotions, professional standing and funding. Hence, the perceived need to "publish or perish".

The emphasis on quantity of publications, rather than quality, has negative implications that are well recognised [1]. It encourages researchers to conduct quick and easy studies that may be of little clinical relevance. It also discourages researchers from being inquisitive and asking important questions that may take many years to answer. Some have claimed that the "publish or perish" mantra provides a disincentive to conduct investigator-led clinical trials. Clinical trials require many years of work from large numbers of people. For that reason, it may be impossible for early career researchers to conduct clinical trials and compete in a highly competitive academic world that values publication rates. Consequently, some researchers are tempted to analyse data they have at hand or can easily acquire. This encourages researchers to tackle research questions that can be answered with the available data, rather than research questions that really matter.
The "publish or perish" mentality also encourages salami publishing; slicing data in its smallest publishable unit $[2,3]$. This can make it difficult to distinguish between the analyses of primary and secondary outcomes. It also makes it hard to distinguish planned analyses from opportunistic post hoc analyses (fishing expeditions, data dredging and $\mathrm{p}$ hacking). There is also the very real risk that the data from one study will be entered multiple times in systematic reviews and meta-analyses.

Researchers need to resist the current high pressures to churn out large numbers of papers. Instead, we must focus on quality science, and do fewer projects but do them well. That is more easily said than done. Readers, journals, peer reviewers, clinicians and the SCI community need to be discerning consumers of research. They can help push back by valuing quality over quantity, because it is high quality research, not high volume research, that the SCI-research world needs most right now.

Publisher's note Springer Nature remains neutral with regard to jurisdictional claims in published maps and institutional affiliations.

\section{References}

1. Ioannidis JP. Evidence-based medicine has been hijacked: a report to David Sackett. J Clin Epidemiol. 2016;73:82-6.

2. Mallon WJ, Kuhn JE, Sperling JW, Edwards TB. Salami publishing. J Shoulder Elb Surg. 2016;25:1559-60.

3. Budd JM, Stewart KN. Is there such a thing as "Least Publishable Unit"? An empirical investigation. Libres. 2015;25:78-85.

\footnotetext{
Lisa A. Harvey

1.harvey@usyd.edu.au

1 University of Sydney, Sydney, NSW, Australia
} 